\title{
Study on the Problem of Anti-Poverty in Rural Education of Yunnan
}

\author{
Guiming Zhang \\ Science and Technology Department, Qujing Normal University, Qujing, China \\ 671818831@qq.com
}

Keywords: Rural education of Yunnan; Anti-poverty; Strategy

\begin{abstract}
Education poverty is particularly prominent in rural areas of Yunnan. Poverty is characterized by knowledge poverty, information poverty and concept poverty. This paper analyzes the following problems in rural education in Yunnan, such as, there is not enough attention to the education itself. Serious insufficient in vestment in Education. The structure of rural teachers is unreasonable, the team is unstable, and the number is insufficient. There are many obstacles in the education of children in the Peasant family. This article puts forward the Countermeasures of anti poverty in Education. Changing ideas and formulating the anti poverty strategy of Education. Innovating rural education investment mechanism. Strengthening the construction of teachers in rural areas. Increasing farmers' income and protecting the educational rights for students in financial difficulties.
\end{abstract}

\section{Background of the Subject}

Poverty is a common problem in human society. Anti-poverty is also a worldwide problem. China is a developing country, and the poor are mainly concentrated in rural areas. Poverty has long plagued the harmonious development of Chinese economy. Yunnan province is located in the southwest border area of China, integrating the special conditions of frontier, nationality and poverty. And the social economy and culture are relatively backward. The contradiction between the backwardness of education and the high requirements of social and economic development is becoming increasingly prominent in Yunnan. Population of Yunnan province is 47 million 400 thousand. According to the survey, the number of poor people in Yunnan was 3 million 630 thousand at the end of 2016. Getting rid of poverty is the dream of all generations of the people of Yunnan from generation to generation. The root cause of poverty in Yunnan lies in the shortage of human capital in rural areas. Education is an important way to shake off poverty for peasants in rural areas of Yunnan. Because the education level of rural population is generally low, which not only lows the level of agricultural productivity, but also restricts their employment space in non-agricultural industries. Basing on Human Capital Theory, education has obvious spillover effect, which will bring notable changes to the individual and society of the educator. Therefore, it is a great theoretical and practical significance to develop education and improve the education opportunities for the poor to eliminate poverty and promote social equity in rural areas in Yunnan.[1]

\section{The Performance of Rural Education Poverty in Yunnan}

Knowledge poverty. It is dominant poverty. "Educational isolation" is the direct cause of knowledge poverty. Due to the poverty, a great number of school-age children are unable to go to school or obliged to discontinue their studies. [2]On the one hand, there is a certain gap between Yunnan's gross enrollment rate and the national average level in terms of culture and education. In 2016, The National Education Development Statistics Bulletin shows that the consolidation rate of nine years compulsory education is $93.4 \%$, the gross enrollment rate of high school is $87.5 \%$, and the gross enrollment rate of higher education is $42.7 \%$. In the same year, Yunnan's nine year compulsory education consolidation rate was $93.5 \%$, the gross enrollment rate of high school is $82.6 \%$, and the gross enrollment rate of higher education is $32.6 \%$. On the other hand, Illiterate and semi illiterate population is larger in rural areas of Yunnan. The data of the sixth national census in 2010 showed that the total population of the province in 2010 was 45 million 966 thousand. Among 
them, there are 2 million 656 thousand people have a university degree, 3 million 850 thousand people have high school (including secondary) education, 12 million 631 thousand people have junior high school culture, and 19 million 944 thousand people have primary school culture. Among people aged 15 and above in Yunnan, the illiterate population is 2 million 770 thousand, and the illiteracy rate is $6.03 \%$.

Information poverty. It is the second feature. In twenty-first Century, a large number of poor people will form serious knowledge poverty due to lack of ability to acquire, communicate, apply and create knowledge and information. They lack the ability to absorb and communicate information, or lack of access. Statistics show that the number of subscribers per year and telephone penetration rate are less than $50 \%$ of the national average in Yunnan rural areas, and Internet penetration rate is lower.[3]

Ideas poverty. It is a kind of recessive cultural poverty. This poverty is mainly manifested in the idea of self-sufficiency in natural economy and semi natural economy, poverty culture in the depths of the poor, The attitude of "cold and rejecting school education" in the mode of natural employment, Lack of enterprising spirit, etc. In the rural areas of Yunnan, farmers have a wide range of ideas, such as conservative backward ideas, lack of enterprising and sense of responsibility, dependence on the government, unwilling to start a business, and fear of taking risks. In order to deal with this situation, it is impossible to solve the problem of poverty by means of material support only. It must be thoroughly solved through universal education and overall improvement of the quality of the population in the poor areas.[4]

\section{Analysis on the Problems of Rural Education Poverty in Yunnan}

Not enough attention to education. Increasing the emphasis on education in poor areas is the key to dealing with education poverty alleviation and other ways to help the poor. Whether the government attaches importance to the education in poor areas directly restricts the function of anti-poverty in education, and affects the process of helping the poor and developing the poor and getting rid of poverty and becoming rich. Therefore, increasing the emphasis on education in poverty-stricken areas is a practical solution to the new situations and problems that arise in the development of education in poor areas. According to the investigation, the government has not paid much attention to the education as an important way of anti poverty because of the long-term nature of education, the sluggishness of the effect and the latent value of the value. Almost all the leaders in poor areas have devoted most of their energy and funds to poverty alleviation projects that promote local growth in the short term. They put the emphasis on poverty alleviation on increasing the short-term income of farmers, and did not attach enough importance to the poverty alleviation of education with more lasting impact.[5]

Great shortage of education financial input. Education without adequate funding, the development of education has become a source of water. Rural areas in Yunnan have too many local financial revenues and too much responsible for their work. Therefore, there is no way to increase investment in education. Statistics show that Yunnan's education budget for public finance in 2016 was 86 billion 412 million yuan. At the end of 2016, the resident population of Yunnan was 47 million 705 thousand. In 2016, the education expenditure per capita for public population in Yunnan was 1811.38 yuan. As a result, there is a big gap between education expenditure in Yunnan and the Middle East.[6]

The structure of rural teachers is unreasonable, the team is unstable, and the number is insufficient. On the one hand, there is also a problem of unreasonable teacher structure in primary and secondary schools in poor rural areas of Yunnan. Teachers have low educational attainment rate, unequal professional title structure and unreasonable academic structure. On the other hand, the mobility of teachers in rural areas is large. The teaching conditions of the city are more superior than that in the countryside. The teachers want to work in the city leading to the vacancy of rural teachers. Because of the deficiency of teachers, many courses are taught by non professional teachers, such as art, music, etc. If teachers are doing well at teaching, they will be allocated to 
better school. As a result, the shortage of primary and secondary school teachers in poor rural areas is even more serious.[7]

The students of the peasant family are blocked more by education. The economic foundation is weak and family income is low in rural areas in Yunnan. It is difficult to guarantee the cost of education for children. Therefore, the farmers' income level is low, and the ability to pay for education is relatively insufficient, which reduces the effective demand for rural education. This is an important reason for the low school enrolment rate of rural school-age children and the decline in the rate of schooling. Although many parents know the importance of education, many people's income is not directly proportional to the level of education. This makes the theory of "useless reading" spread in poor rural areas.

\section{Countermeasures and Suggestions on Anti Poverty in Rural Education in Yunnan}

Changing ideas and formulating the anti poverty strategy of Education. To pay more attention to education in rural poor areas. We should not only put it in the central position, but also put it into practice. More attention and funding should be given to students in remote areas, poor students, and physically handicapped students. The government should formulate the anti - poverty strategy of education. Integrating education anti poverty into economic and social development strategy and master plan. Increasing government investment, Integrating sector industry resources, organizing social forces to participate in the poverty alleviation of Education, and Carrying out the goal responsibility system and evaluation system for poverty alleviation through education.[8]

Innovating of rural education investment mechanism. The establishment of a sound funding mechanism for education is the key to the healthy development of education in rural areas and the equalization of urban and rural education. Education investment in poor rural areas of Yunnan should not be blindly carried out. The emphasis is on basic education and vocational education in rural areas. The government should ensure the growth of compulsory education funds in accordance with the requirements of the public financial system. In addition, government should ensure that children of every poor family can enjoy compulsory education and relieve the worries of children from poor families. The government should also make targeted educational compensation for the poverty-stricken population in the vocational education stage.[9]

Strengthening the construction of teachers in rural areas. We should optimize the structure of teachers' academic qualifications and professional titles, expand the exchange of teachers, and achieve the sharing of high-quality educational resources. Firstly, By raising academic qualifications, the teachers should further master scientific knowledge and improve professional quality, so as to achieve life-long learning from defensive learning. Secondly, we should give priority to supplement normal students to primary and secondary school to teach in poor rural areas, and alleviate the serious shortage of professional teachers. Thirdly, stabilizing the teachers in poor rural areas. We should adopt special preferential policies to establish a subsidy system for teachers in rural primary and secondary schools. Ensuring the full payment of wages, so that teachers can work at ease.[10]

Increasing farmers' income and protecting the educational rights and interests of students with financial difficulties. The realization of children's educational interests and the increasing of enrollment rate in poor families depend on the increase of farmers' income. Therefore, in addition to continue to implement the policy of agricultural subsidies, welfare and social security in the poor areas, the government should take some concrete measures to increase the income of farmers.

\section{Acknowledgements}

Scientific research foundation of Yunnan Provincial Department of Education in 2017, project name: Research on the anti-poverty problem of rural education in Yunnan under the structural reform of supply, project number:2017ZDX146. 


\section{References}

[1] D.W.Liu: Research on the Problem of Anti-Poverty in Rural Education in the western poor counties of Jilin Province.(MS.D.,Northeast Normal University,China 2014),p.8-11..

[2] X.J.Wang: A Study of Anti-Poverty in Rural Education in Western China.(MS.D.,Northwest Agriculture and Forestry University, China 2009),p.11-18.

[3] X.F.Zhang: Research on the Current Situation of Rural Education.(MS.D.,Huazhong Normal University,China 2013),p.2.

[4] .Z.Gao: Research on the Problem of Accurate Poverty Alleviation in Rural Education.(MS.D.,Jilin University of Finance and Economics, China 2013), p.21.

[5] X.Wu: Journal of Yunnan Institute of Finance and Commerce, Vol.21(2005)No.12,p.122-126.

[6] J.Zhang: Friends Magazine for National Prosperity, Vol.12(2015)No.6,p.35.

[7] Y.T.Guo: The reference of political teaching in middle school, Vol.16(2016)No.12,p.80.

[8] D.M.Gong: Journal of Chifeng University, Vol.29(2008)No.6,p.170-172.

[9] M.L.Zhao: Journal of theoretical discussion, Vol.23(2006)No.5,p.100-102.

[10] G.Li: Journal of Kunming University of Science and Technology, Vol.1(2001)No.4,p.94-96. 